\title{
THE USE SUPERORDINATE CONCEPT IN THE MEANING OF SPEECH
}

\author{
Dicky Widiya Perkasa ${ }^{1}$, Iman Santoso ${ }^{2}$ \\ ${ }^{1}$ IKIP Siliwangi \\ ${ }^{2}$ IKIP Siliwangi \\ ${ }^{1}$ Iko.dicky@gmail.com, ${ }^{2}$ imansantoso515@gmail.com
}

\begin{abstract}
Words have been existed since hundreds of years ago the implicit meaning of a words can indicate an expression of someone Through human words can communicate with various kinds of meanings in their conversation, in the concept of writing the researcher will explain a concept of superordinate which as a form of word level the highest which has the earliest meaning of each word, The good thing that can be learned in this superordinate concept is that the meaning of the word will not become complicated, for example "The fish is very ferocious", then what fish does it mean that might be sharks or dolphins, in fact sharks are wild fish, but fish dolphins are not fierce, from which the superordinate has not been able to represent the above words so that in the form of the next two concepts which further pursing the word "fish" above into "The shark is very ferocious" the shark refer to the Basic concept and then it can be more specific from Subordinate to be like this "The white shark is very fierce" (white shark) is subordinate. In another case why the researcher takes the concept from this superordinate is to explain that a meaning in the word has owned level and then the words will not always have the same meaning in delivering their purpose, regardless of the daily conversation pretty much people used "Basic and Subordinate" due the meaning is more referring and precise.
\end{abstract}

Keywords: Meaning, Word, Concept, Communitacion

\section{INTRODUCTION}

Superordinate is the terms that higher-up or more general in a hierarchical scale this term early as structure of conceptual knowledge organization and also superordinate can be called ( hypernyms, anaphoric nouns, or discourse-organizing words). One step down there are Basic concepts typically represent the characteristics of single objects and the last one is subordinate as a type that is more specific in meaning, in a statement (Biederman,1987; Tversky \& Hemenway, 1984) as cited in (M. Borghi, Caramelli, 1385). Superordinate level concepts convey both functional information, after the superordinate meaning is then lowered into two more levels which are "Basic" and "Subordinate" in the concept these two levels deliver a more specific meaning in the word (Tversky \& Hemenway,1984; Tversky, 1989) as cited in (Mehawesh, 2000) and general knowledge (Barsalou, 1991) about the objects they refer to. Both basic and subordinate level concepts, such as 'dog' and 'hound', that can be directed from the statement that the two concepts of basic and Subordinate are indeed more conical. Conversations that are often done by every human being do contain various kinds of meanings, if each word they say is analyzed by "Superordinate" the concept may not be affected by how much is spoken but here is not how much will be in the language.

In writing this journal the researcher discussed how the concept of the superordinate can be a meaning which is then used in referring to something else. Different conceptual views have been expressed according to which concepts convey perceptual information regardless of the 


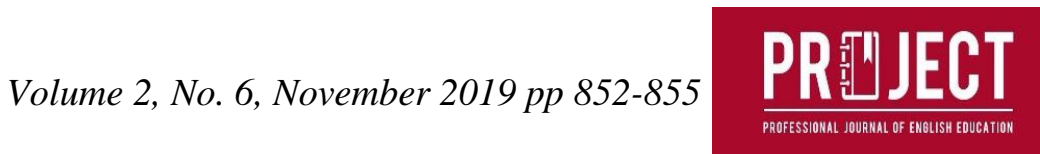

hierarchical level (Barsalou, 1993; 1999; Barsalou, Simmons, Barbey, \& Wilson, 2003; Glenberg, 1997; Goldstone \& Barsalou, 1998) Thus, Smith \& Heise (1992) and Jones \& Smith (1998) as cited (McAnsh, 2004) have shown that Perceptual information helps to distinguish different types of higher level concepts as texture information and information about movements, characterize very general superordinate concepts such as 'Basic' and 'Subordinate' concepts.

Meaning can be understood through a word, but if the word used contains a less precise meaning, it arises confusion for the listener, therefore the word must indeed use the level of "superordinate" for example (I really like the colors of the rainbow) the statement is correct because "colors" has stated a great meaning from the rainbow itself, the example that less precise (I really like the red, yellow, green and blue from it) why is this not right according (Heit \& Barsalou, 1996, De Wilde, Vanoverberghe, Storms, \& De Boeck,2003) as cited in (Solène Kalénine and Françoise Bonthoux, 2006) During a superordinate concept is activated, the information related to the example need to be activate as well. Well that the information conveyed can be understood, due a word that is less precise can cause inappropriate meanings

In other cases the difficulties to be understood by the interlocutor are the meaning of superordinate itself because superordinate can't always be used in an intent as an example (I really like that food) "food" here can be a statement that is difficult to understand because of food as what is intended by the person, this is in accordance with what is explained by (Murphy and Smith) (1982) as cited in (Conway, M. A., Kahney, H.B., Bruce, K., \& Duce, 1991) that superordinate level concepts are responded to more slowly than basic level concepts because their activation also triggers the activation of several example of a category marked with perceptual information.

\section{METHOD}

This research analyzed superorditane from Speech activities as a referring source on superordinate, the research use Qualitative method, Qualitative research is an approach for exploring and understanding the meaning from the individual or groups a scribe for social human problems processes, the research involving questions and procedures that arise (Creswell, 2008), in taking data the researcher use Speech activity video that talk about the hobby, after watch the video the researcher grouping every words that related with Superordinate and analyze it, As for some things related to superordinate, namely two concepts which are one level below in the explanation of these two things are complementary when the active superordinate of these two concepts is referred to as (basic and subordinate). The role of this concept is to specify a meaning of the word begin with the superordinate due the correlation of the two concepts is very needed when the Superordinate starts to be used well that the meaning to be delivered become more structured in the purpose of examining this superordinate the researcher would like to convey that the structure of the word is true exist through the three concepts of the word it will be more conical in its meaning and of course the superordinate is the highest level of word meaning Twelve superordinate level concepts were selected. They all count nouns that their examples are marked by the right inclusion class relationship (Markman, 1985;Wisniewski, Imai \& Casey, 1996). For each Superordinate level concept, e.g. 'toy' and 'bird', one of its basic level exemplar, e.g. 'doll' and 'swallow', was added. Each of the 24 concept nouns obtained is paired with two adequate locations, both of the Scene-like types (e.g. 'swallow/bird-8 sky', 'doll/toy-nursery') or of the Object-like kind (e.g. 'swallow/bird-nest' or 'doll/toy-box'). To check the adequacy of differences between the location of the scene and the 
object. Based on the analyzed the researcher found several events that have been arranged in the table below, the occurrence of the emergence of superordinates was obtained from a video source.

\section{RESULTS AND DISCUSSION}

\section{Results}

The researcher analyzed the superordinate of a video speech activity, in the video there are several concepts of using superordinate (Conversation, 2014).

Table 1 The Data of Superordinate

\begin{tabular}{|c|c|c|c|c|}
\hline No & $\begin{array}{l}\text { Event } \\
\text { Times }\end{array}$ & $\begin{array}{c}\text { Superordinate } \\
\text { Active }\end{array}$ & Transcript & Explanation \\
\hline 1 & $0: 18$ & $\begin{array}{l}\text { Hobbi } \\
\text { es/Hob } \\
\text { by }\end{array}$ & $\begin{array}{l}\text { when the man says } \\
\text { hobbies to the woman, } \\
\text { then the woman responds } \\
\text { by asking about whatever } \\
\text { hobbies you like, the man } \\
\text { says he likes collecting } \\
\text { stamps and beer }\end{array}$ & $\begin{array}{l}\text { the word hobbies refers to } \\
\text { the next meaning followed } \\
\text { by "stamps and beer" }\end{array}$ \\
\hline 2 & $0: 43$ & World & $\begin{array}{l}\text { the man said he } \\
\text { collected every stamp } \\
\text { from around the world } \\
\text { and besides that he could } \\
\text { visit every country in the } \\
\text { world }\end{array}$ & $\begin{array}{l}\text { the meaning from this } \\
\text { (world) is very broad, when } \\
\text { it says the world of other } \\
\text { things will emerge like } \\
\text { countries, regions and others }\end{array}$ \\
\hline 3 & $1: 34$ & Place & $\begin{array}{l}\text { the man said he collected } \\
\text { beer cans from every } \\
\text { place he visited }\end{array}$ & $\begin{array}{l}\text { If observed from the word } \\
\text { "from every place" the place } \\
\text { word will be more dominant } \\
\text { as the superior because the } \\
\text { opening meaning of the } \\
\text { conversation about this beer } \\
\text { starts to be expanded when } \\
\text { the man says "from every } \\
\text { place" }\end{array}$ \\
\hline 4 & $1: 50$ & Read & $\begin{array}{l}\text { This time the man asks } \\
\text { the woman's hobbies, } \\
\text { then the woman says she } \\
\text { likes reading }\end{array}$ & $\begin{array}{l}\text { The word "reading" from the } \\
\text { woman leads (Bestseller and } \\
\text { scene). Because the word } \\
\text { reading is also a question by } \\
\text { the man. }\end{array}$ \\
\hline 5 & $2: 07$ & Science & $\begin{array}{l}\text { The guy says what kind } \\
\text { of Science do you like to } \\
\text { read? }\end{array}$ & $\begin{array}{l}\text { the word "science" that the } \\
\text { man asks the woman covers } \\
\text { many things and can be said } \\
\text { as a superordiante because } \\
\text { after that the woman } \\
\text { explains what kind of } \\
\text { knowledge she likes as } \\
\text { "Nature" and "electronics" }\end{array}$ \\
\hline
\end{tabular}

\section{Discussion}

In the video the researcher found several concepts from the superordinate used by female and male speakers that the concepts are: (Hobby, world, Place, Read and Science) because the 
meaning in the word implies which must be followed by the following two concepts for example when the woman says she likes the hobby of "reading" then the man says you like to read about what, the response of the man is one proof that the meaning of the use of the superordinate cannot always be alone as said by (Heit \& Barsalou, 1996, De Wilde, Vanoverberghe, Storms, \& De Boeck,2003) During a superordinate concept is activated, the information related to the example need to be activate as well. therefore the woman responds again by answering she likes to read natural sciences and electronic sciences, the words "read natural sciences" and "electronic sciences" are two responses that are called subordinates, which means that after the appearance of the superordinate subordinate appears as a response, because the concept of this superordinate cannot stand singly, the reason is that the meaning of the superordinate can be connected properly, because the two levels below the superordinate not only give another meaning but can connect the following word meanings from the superordinate itself.

\section{CONCLUSION}

Well the purpose of this Journal is to explained the used of the meaning from superordinate concept which is actually not always able to stand alone even though it is the highest word level but superordinate will not be a complete meaning in a good communication by knowing how to superordinate it, because the essence of superordinate has two concepts of meaning which have levels below which are basic and subordiante with both superordinates can be used properly and accurately, besides that superordinate has many roles in delivering the meaning of words to other objects such as colors, animals and others this can be seen in a around us.

\section{ACKNOWLEDGMENTS}

Thank you for the Almighty God, thank you for the colleagues who want to help and give their time, thanks also to my family who give a lot of physical assistance and support Hopefully with this journal, it can be useful for everyone who will be looking for the same material, and thank you to all the experts who have explained about superordinate

\section{REFERENCES}

Conversation, L. E. (2014). Learn English Conversation Unit 11 Hobbies. Retrieved from https://www.youtube.com/watch?v=-UX0X45sYe4

Conway, M. A., Kahney, H.B., Bruce, K., \& Duce, H. (1991). Imaging objects, routines, and locations.

Creswell, J. W. (2008). Educational research tive and qualitative research. $3 \mathrm{rd} c d$.

M. Borghi, Caramelli, A. S. (1385). Superordinate level concepts and scenes Conceptual information on objects' locations. 302.

McAnsh. (2004). Superordinate. $\quad$ Retrieved from http://sana.aalto.fi/awe/grammar/superordinate.htm

Mehawesh, D. M. (2000). No TitThe Role of Superordinates, General Words and Collocates in the Translation of Political Speeches le.

Solène Kalénine and Françoise Bonthoux. (2006). The Formation of Living and Non-Living Superordinate Concepts as a Function of Individual Differences. Vol.2. Retrieved from https://journals.openedition.org/cpl/1066 